\title{
A geographical information system approach for analysis of surface areas in the context of renewable energy resources
}

Oudin, A., Sprake, D., Vagapov, Y. and Simonova, O.

This is a paper presented at the 2017 IEEE Conference of Russian Young Researchers in Electrical and Electronic Engineering (EIConRus)

Copyright of the author(s). Reproduced here with their permission and the permission of the conference organisers.

\section{Recommended citation:}

Oudin, A., Sprake, D., Vagapov, Y. and Simonova, O. (2017), 'A geographical information system approach for analysis of surface areas in the context of renewable energy resources', in Proc. 2017 IEEE NW Russia Young Researchers in Electrical and Electronic Engineering Conference, Moscow, Russia, 1-3 February 2017, pp. 513-517. doi: 10.1109/EIConRus.2017.7910604 


\section{A Geographical Information System Approach for Analysis of Surface Areas in the Context of Renewable Energy Resources}

\author{
Alexandre Oudin, David Sprake, Yuriy Vagapov \\ Glyndwr University \\ Wrexham, UK
}

\author{
Olga Simonova \\ National Research University of Electronic Technology \\ Zelenograd, Moscow, Russia
}

\begin{abstract}
The ability to assess an area for the potential of different renewable energies is governed by a wide range of technical, topographic and environmental variables. This paper discusses modelling these differing constraints for renewable energy potential and then to visualise results on an interactive map. A layered GIS is used with the UK as a location test area. The results compared different renewable energies potential for the same location in the form of $\mathrm{kWh} / \mathrm{m}$. On land it was found it is often possible to harness combined renewable energy from ground (solar, bioenergy), at altitude (wind energy) and underground (geothermal, GSHP) at the same time discovering increased multipliers of energy production and land use efficiency.
\end{abstract}

Keywords—renewable energy, spatial mapping, GIS approach, technical potential

\section{INTRODUCTION}

Energy management has become one of the main challenges for all countries in the world. The economical and human development require a significant quantity of energy. However, this economic growth is often combined with the increase of greenhouse gas emissions [1]. It is now a consensus that these gas emissions are responsible to the global warming issue. This problem has been now fully acknowledged by globally by the majority of scientists and politicians [2]. The development of renewable sources of energy is crucial to limit carbon emissions responsible for the global warming [3], [4].

There are many sorts of renewable energy sources. The common link between them is the utilisation of basic physics laws. Despite the diversity of these energies they are often simplified in two forms: Kinetic energy and gravitational energy given in the measure Joules. In order to compare the UK renewable energy potential of electricity production, a mixed research method (qualitative and quantitative) has been applied to create a multidisciplinary framework. The project's purpose is to use a GIS (Geographical Information System) approach to display on a territory map the technical potential from different renewable energy sources and by comparing them, optimising "green" energy production. Both approaches use a numerical modelling of data and their spatial analysis using a GIS systems approach to enhance clarity of results and decision making. The model could help to visualise multifaceted information relationships directly between spatial disposition and resources availability [5].

The sources considered are sown in Fig. 1.

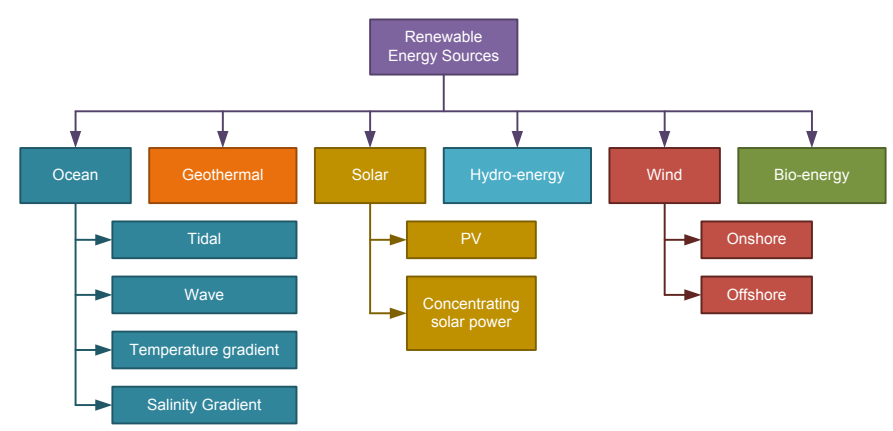

Fig. 1 Renewable energy sources

\section{RESEARCH METHODOLOGY}

A GIS approach is used to display a territory map of the technical potential from different renewable energy sources by finding a way to compare them. The approach is through the numerical modelling of data and their spatial analysis using GIS a systems approach consisting on compiling layers of data in order to create an interactive map. In cases where databases are already available the GIS system uses these tables to convert into layers and compile to create the map. In the case of existing databanks cannot provide this information, it was possible to create new databanks to be used in the system. This paper has been conducted mainly using the latter data extraction method because data needed had to be created before. The methodology used during this project has consisted on developing a specific variable to compare the complexity using different sources of renewable energy. From this a numerical approach has been conducted to calculate technical potential produced by all technologies concerned in this project. Finally, the GIS approach describes a scheme to display in an interactive manner this information covering the UK territory.

Estimating the technical potential for a renewable energy depends on a wide range of characteristics specific to the technology. To compare these resources, it is essential to define in a first instance the study area and boundaries of this 
research. The place required to install systems and assets requested to produce electricity force us to find a common and relevant variable to be able to compare significantly these sources. The baseline has been to find a key variable to collate small-scale technology.

The Technical Potential is the maximum annual energy that could be extracted from the accessible part of the available resource using current mature technology. While this could change with technological progress, it may be limited by basic accessibility constraints. Subsequently, the practicable potential is the technical potential reduced by taking into account constraints when using distributing the energy (transportation, access to the grid etc.). Finally, the Economical Potential is the amount of the technical potential that is economically viable [6]. This study considers the technical potential degree of detail. A key purpose of this research paper is to contribute to the decision-making stage of developing new renewable energy site installations in the UK.

To map the renewable energy potential, three categories of data have been collected. Primary data sources include technical characteristics of all renewable energy equipment. This information has been gathered by creating a benchmark study from renewable installation companies. Other primary data sources consist on compiling raw weather data.

Concerning solar energy, the yearly average of global irradiation on a horizontal surface $\left(\mathrm{kWh} / \mathrm{m}^{2}\right)$ has been collected using the PVGIS program developed by the Institute for Energy and Transport (IET) of the European Commission. It covers data collection from the period 1998 to 2011 [7]. The format of the map projection used is the geographic (latitude/longitude) ellipsoid WSG84 (World Geodetic System 1984).

Concerning wind energy, it has been divided into two sections: onshore and offshore. Wind speeds onshore data has been stockpiled from RenSMART databases. It includes wind speeds yearly average at 10, 25 and 45 metres above the ground level for each $\mathrm{km}^{2}$ of the UK territory covering the period 2000-2010. The format of these data is Easting/Northing-OSGB36 system [8]. Wind speed offshore raw data has been collected using the ABPmer data collection. It characterises the average annual wind speeds at 100 metres above the sea level and it covers data recorded from 2001 to 2008 [9]. Format of the map projection uses the latitude/longitude (decimal) WSG84.

Concerning hydro resources have been collected from Water Resources GIS databank covering Wales and England. It concerns small-scale hydroelectric generation systems. Accessible data include 1989 period and use the National grid Reference (NGR) - OSG36 format system.

Secondary sources of data consist on gathering technical and environmental constraints of each renewable energy in order to refine location suitability. It includes special protected areas, national reserves, wetlands, woodlands and mountains for solar PV systems. Regarding wind energy, technical restrictions are for example urban areas, railways and roads existence etc. All the previous data is employed as GIS layers and can be combined through OS MasterMap, Strategi, English
Nature, Lle Geo-Portal for Wales, LIDAR, SAR, Water Resource GIS, UK government

Open data sources and directly from CNES satellites. Finally, the base map and the UK's mesh unite the territory source of data. ESRI base map of the UK may be used to compose background of the map. The territorial grid resolution chosen is one $\mathrm{km} 2$. This resolution is due to meteorological data availability. In this research, the Github's UK territory mesh has been selected. It is based on NGR (National Grid Reference) format and it uses the OSGB36 system to project data.

Considering the UK is the defined study area, it reduces the scope of technologies operable for this study. Indeed, concerning ocean energy applications such as OTEC (Ocean Thermal Energy Converter) which using the water temperature gradient, climatic conditions are not satisfied in the UK [10]. Furthermore, despite tidal, wave and salinity gradient technologies potentials are prevalent in the UK [11], the recent take-off of the development of these equipment is not adequate with this project objectives. Likewise, the lack of information due to the underdevelopment of these resources prevents the utilisation of relevant data to estimate electricity production. Concentrated solar power (CSP) structures are not adapted as well to this study because of the insufficient solar irradiation in the UK [12]. Regarding geothermal energy, the UK does not undergo tectonic or volcanic activity and have only several geological features that could be potential geothermal prospects [13]. Most of British geothermal energy derives from urban systems development to provide heat energy [14].

Bio-energy covers a wide range of technologies such as bio-fuels production, biomass, waste energy generation, or livestock slurry energy. It can produce electricity and heat generation, both at the same time [15], but for technical reasons this is not considered in this study. In effect, bioenergy plants may be installed almost in most locations and do not directly depend to the quantity of resources available on the site. These resources are often gathered from different areas. Hence, it is technically too constraining to compare these technologies to the others based on the methodology used in this paper. For all these reasons, geothermal, ocean, CSP, thermal solar and bioenergy sources will not be considered in this paper. Therefore, this paper will focus to compare four diverse renewable energy sources: Solar PV, Onshore and Offshore Wind energy and hydroelectric energy, Solar PV and hydro technologies ranging from $500 \mathrm{~kW}$ to $5 \mathrm{MW}$ systems.

It is crucial to define a pertinent indicator that would be able to consider either the scale of the system and the technical potential generated. This unit is the $\mathrm{Wh} / \mathrm{m}^{2} / \mathrm{y}$ and in most of studies, technical potential estimations are based on a model using a specific system and these are based on an idealistic vision of renewable energy of which margins of error in these cases are very unpredictable. As such this study uses an interval way to compare energies. The purpose is to estimate the smallest and biggest quantity of energy by type of sources that could be extracted with the current technologies existing by type of resource. 
The result has to show the comparison of renewable energy source using the common unit $\mathrm{kWh} / \mathrm{m}^{2} / \mathrm{y}$ displaying the interval of electricity produced by type of sources.

\section{RESEARCH METHODOLOGY}

The GIS Geo-referencing system approach imposes the comprehension of three fundamental topics: Geo-referencing, Vector mode, Raster mode. This is the first step in a GIS method. The aim was to create a mesh of the area of study to delimitate the boundaries.

\section{A. Solar Resource}

Solar resources have been collected using the PVGIS program database [16]. It was built by the European Commission and developed from climatologic data homogenized for Europe.

\section{B. Wind Resource}

Onshore wind speeds come from the BERR speed Database [8]. It results from a flow model that assesses the effect of topography on wind speed. Datasheet used to represent all UK lands gather more than one million wind speeds $(\mathrm{m} / \mathrm{s})$ values taken at 45 meters height above the ground level. Wind speed values allow the calculation of the wind resource available. An example of the wind map is shown in Fig. 2.

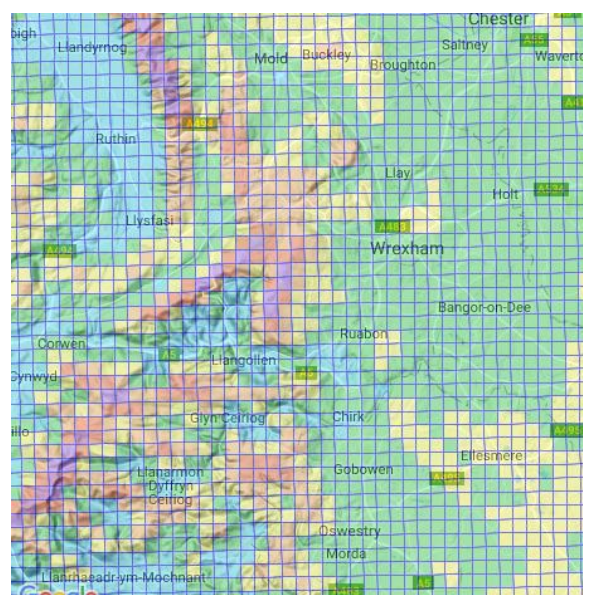

Fig. 2. NOABL Wind map centred on Wrexham [8]

\section{Hydro Resource}

Hydropower characteristics have been extracted from [17].

\section{GIS Baseline}

GIS is an integrated collection of computer systems used to analyse, create, acquire, store, edit, transform, view, and distribute geographic data [20]. It facilitates the acquisition, management, manipulation and generates spatially referenced data to solve complex planning and management problems. The GIS approach includes three main components: The data collection (explained in the previous section), the analysis domain, and the communication domain. The phases of creation of the interactive map are shown in Fig. 3. Following this flow chart, it is possible using the GIS software functions to retain data in the layer wanted.

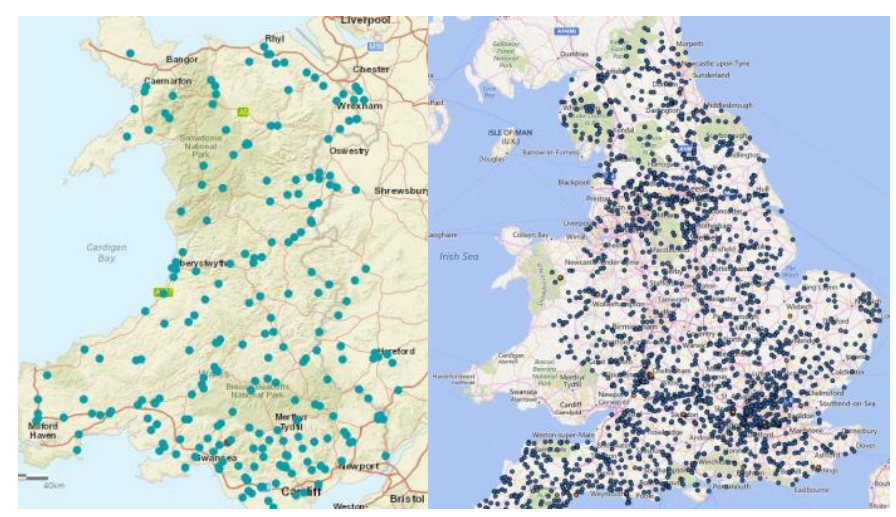

Fig. 2. River positions in the UK [18], [19]

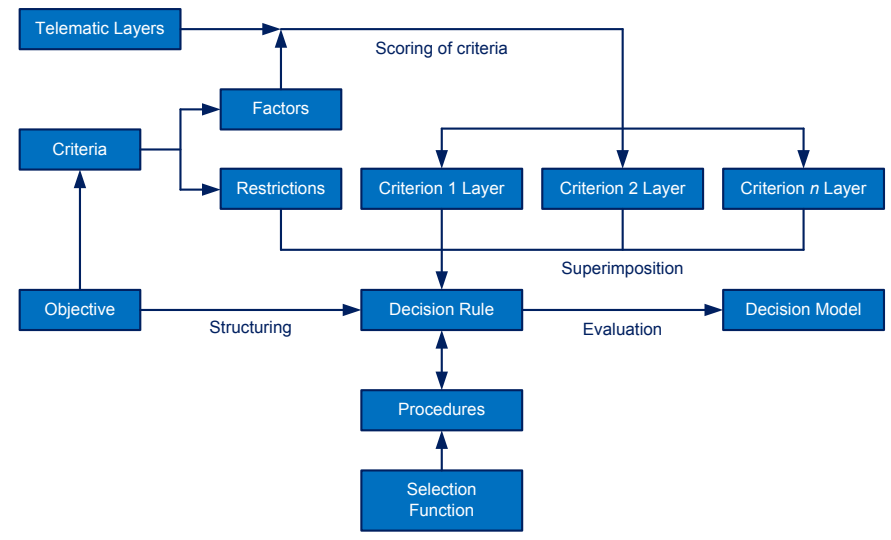

Fig. 3. Phases of creation of the interactive map [21].

\section{RESULTS AND ANALYSES}

This paper provides analyses of the numerical model results using three example case studies which is indicative of how the model may be used:

1) The utilisation of an interval is to analyse through the onshore wind energy numerical simulations.

2) Compares wind, solar and hydro technical potential in an example site in the UK.

3) The results obtained on a site where only solar and wind energy can be exploited.

\section{A. Case Study 1: Impact of Wind Turbine's Size}

Analysis of the technical power provided by a wind turbine. This study has been carried out using data from a site in Wales located at the latitude $53.2^{\circ}$ and longitude $-3.4^{\circ}$. The initial configurations have been presented in Table I.

TABle I CONFiguration for CASE Study 1

\begin{tabular}{|l|l|l|l|l|l|}
\hline $\begin{array}{l}\text { Nominal } \\
\text { power } \\
\text { (MW) }\end{array}$ & $\begin{array}{l}\text { Hub } \\
\text { height } \\
(\mathbf{m})\end{array}$ & $\begin{array}{l}\text { Rotor } \\
\text { Diameter } \\
(\mathbf{m})\end{array}$ & $\begin{array}{l}\text { Mean } \\
\text { Efficiency }\end{array}$ & $\begin{array}{l}\text { Capacity } \\
\text { factor } \\
\mathbf{( 2 0 1 4 )}\end{array}$ & $\begin{array}{l}\text { Wind } \\
\text { Speed at } \\
\mathbf{4 5 m}(\mathbf{m} / \mathbf{s})\end{array}$ \\
\hline 0.6 & 75 & 52 & 0.27 & 0.268 & 6.2 \\
\hline 5 & 140 & 132 & 0.389 & 0.268 & 6.2 \\
\hline
\end{tabular}


The results shown in Table II reveal that the ground surface occupation of a wind energy system can be reduce if the wind surface is increased. It confirms the trend of industries to produce ever increasingly larger systems. Furthermore, from these results, it can be deduced that for an available area, it is probably preferable to install the biggest system possible rather than more, smaller systems.

TABle II Results of CASE Study 1

\begin{tabular}{|l|l|l|l|l|}
\hline $\begin{array}{l}\text { Estimated } \\
\text { Wind speed } \\
\text { at hub } \\
\text { height } \mathbf{( m / s )}\end{array}$ & $\begin{array}{l}\text { Technical } \\
\text { Potential } \\
\text { per system } \\
\mathbf{( M W h )}\end{array}$ & $\begin{array}{l}\text { Number of } \\
\text { Turbines } \\
\text { per } \mathbf{k m}^{2}\end{array}$ & $\begin{array}{l}\text { Surface of } \\
\text { optimised } \\
\text { number of } \\
\left.\text { turbines } \mathbf{( m}^{2}\right)\end{array}$ & $\begin{array}{l}\text { Technical } \\
\text { power per } \\
\mathbf{m}^{2} \\
\mathbf{( k W h} / \mathbf{m} \mathbf{2} / \mathbf{y})\end{array}$ \\
\hline 6.9 & 281 & 4 & 849,487 & 1.32 \\
\hline 7.8 & 3793 & 1 & $1,000,000$ & 2.77 \\
\hline
\end{tabular}

B. Case Study 2: Comparison Between Solar, Wind and Hydropower Energy

This case study compares wind, solar and hydro technical potential in an example site in the UK. The place chosen for this case study is in Scotland (Latitude: 57.5\%/Longitude: $-4.6^{\circ}$ ), and it is a one $\mathrm{km}^{2}$ site able to install these three sorts of renewable energy systems.

TABLE III Results OF CASE STUdy 2

\begin{tabular}{|l|l|l|l|}
\hline Scotland & $\begin{array}{l}\text { Minimum } \\
\text { Technical } \\
\text { Potential } \\
\left.\mathbf{( k W h} / \mathbf{m}^{2} / \mathbf{y}\right)\end{array}$ & $\begin{array}{l}\text { Maximum } \\
\text { Technical } \\
\text { Potential } \\
\left(\mathbf{k W h} / \mathbf{m}^{2} / \mathbf{y}\right)\end{array}$ & $\begin{array}{l}\text { Capacity } \\
\text { Factor (2014) }\end{array}$ \\
\hline Offshore Wind & 1.63 & 3.42 & 0.262 \\
\hline Solar PV & 10.05 & 29.29 & 0.089 \\
\hline Hydroelectric & 289.4 & 337.63 & 0.413 \\
\hline
\end{tabular}

The analysis shows important differences between the three resources. The hydroelectric power prediction is considerably more compared to the wind and solar PV systems. Several hypotheses can explain these figures. The most likely is the vague assumptions made for the hydroelectric numerical model. The mathematical model assumes that only one hydroelectric system can be installed on a one $\mathrm{km}^{2}$ site. In addition, a GIS Approach does not look at ways to compare the complexity and areas using different renewable energy occupied by the two hydroelectric systems selected was assumed. In reality, the surface needed for each system depends of the area configuration.

\section{Case Study 3: Wind or Solar Energy?}

The results obtained on a site where only solar and wind energy can be exploited. The UK has been spilt into four scenarios for this case study as follows and two (a and b) are discussed in this paper.

For each scenario sunlight has been considered as a defined constant and the impact of wind velocity variations on the electricity produced has been compared to solar PV energy outputs. In addition, as assumed in the theoretical model, about $30 \%$ of a rural zone can be covered with solar PV panels. This third case study has focused on comparing wind onshore and solar PV panels in a clear area where the Hellman coefficient is 0.2 . In addition, the performance ratio for solar $\mathrm{PV}$ is $48 \%$.

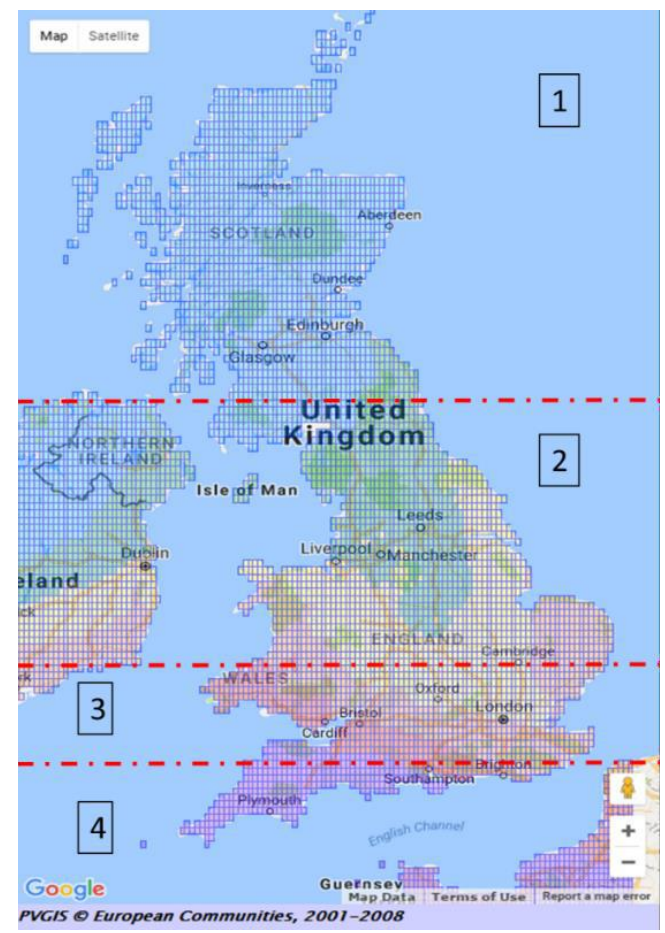

Fig. 4. UK splitting for case study 3.

Scenario (a). The first scenario (1) on map above (Fig. 4) considers that the solar irradiance average is $2.8 \mathrm{kWh} / \mathrm{m}^{2} /$ day. Based on solar PV technical potential model, the minimum electricity expected is $10.31 \mathrm{kWh} / \mathrm{m}^{2} / \mathrm{y}$ and the maximum is $30.04 \mathrm{kWh} / \mathrm{m}^{2} / \mathrm{y}$. The wind velocity impact on the electricity supply has been represented through the following chart. The capacity factor selected is $26.2 \%$ for wind energy, which is the Scottish average coefficient.

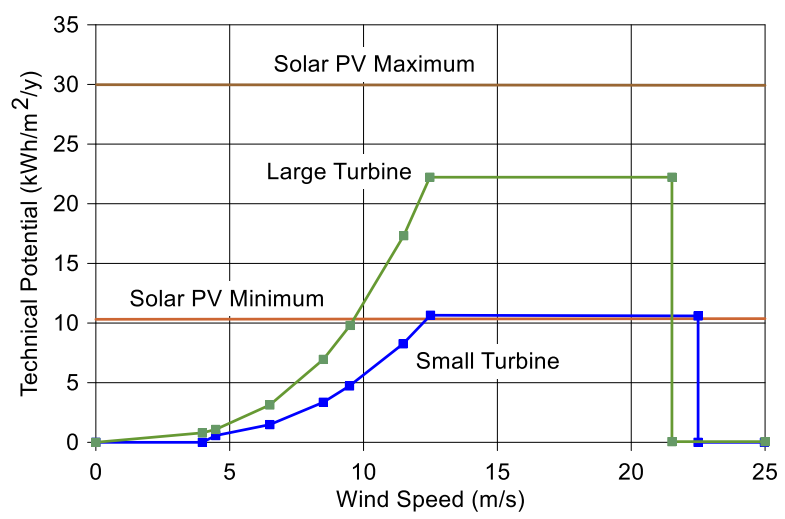

Fig. 5. Comparison of solar and wind energy in scenario (a) (Scotland).

Scenario (b). Representing the South of the UK (4 on map in Fig. 4.) considers that the solar irradiance average is $3.4 \mathrm{kWh} / \mathrm{m}^{2} /$ day. The minimum solar PV technical potential is $12.52 \mathrm{kWh} / \mathrm{m}^{2} / \mathrm{y}$ and the maximum is $36.48 \mathrm{kWh} / \mathrm{m}^{2} / \mathrm{y}$. The capacity factor selected is $26.6 \%$ for wind energy, which is the English average coefficient. The evolution of wind energy 
technical potential depending to the wind velocity is presented in the next graph.

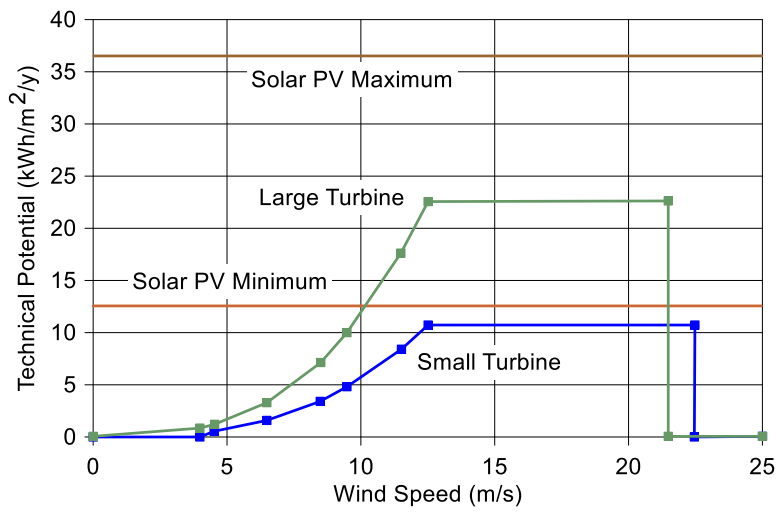

Fig. 6. Comparison of solar and wind scenario (b) (South of England)

The above graphs illustrate that the wind technical potential is practically similar to all regions. In addition, the maximum solar panel outputs (summer) are as expected better the further south the geographical location considered. These results have to be considered carefully. Indeed, it does not prove that solar PV is a better technology than wind onshore in the UK.

It proves that in specific conditions - if at least $30 \%$ of a one $\mathrm{km}^{2}$ is suitable to install solar PV systems - then solar PV can produce as much or more electricity than a wind system compared to the area occupied by these systems. In addition, the energy provided by the both resources are estimated on an average per day, and solar PV can produce electricity only during the day rather than wind energy can do it during the night too. However, these results can vary from one place to another depending to the local topographic restrictions and to the exposition to natural characteristics (wind shear and solar orientation).

The numerical model carried out on the comparison of RES technical potential has provided valued information on the way to compare different sorts of energy. Some results obtained indicate assumptions chosen for the study might be incorrect and further research needs to be completed to tweak the models onto higher accuracy.

\section{CONCLUSION}

Procedures to create the interconnections between all layers have been considered. The method chosen to conduct this study was to compare RES technical potential, but it could be equally advantageous to investigate a way to combine different renewables in a three dimensional study of the same area. In fact, on a land it is often possible to harness renewable energy from ground (solar/bioenergy) to altitude (wind energy) and underground (geothermal) vastly increasing the potential $\mathrm{kW} / \mathrm{m}^{2}$ potential.

\section{REFERENCES}

[1] IEA, "Energy statistics manual," International Energy Agency, 2013 [Online]. Available: https://www.iea.org/publications/freepublications/ publication/statistics_manual.pdf [Accessed 15 Aug. 2016].

[2] Cop21.gouv.fr, "COP21. More details about the agreement," 2015. [Online]. Available: http://www.cop21.gouv.fr/en/more-details-aboutthe-agreement/. [Accessed 15 Aug. 2016].

[3] M. Bilgili, A. Ozbek, B. Sahin, A. Kahraman. "An overview of renewable electric power capacity and progress in new technologies in the world," Renewable and Sustainable Energy Review, vol. 49, pp. 323-334, Sept. 2016.

[4] K. Caldeira, A. Jain, and M. Hoffert. "Climate sensitivity uncertainty and the need for energy without CO2 emission," Science, vol. 299, no. 5615, pp. 2052-2054, Mar. 2003.

[5] C. D. Yeager, T. Steiger. "Applied geography in a digital age: The case for mixed methods," Applied Geography, vol. 39, pp. 1-4, May 2013.

[6] G. Boyle, Renewable Energy. Power for a Sustainable Future, Oxford: Oxford University Press, 2012.

[7] IET, "Satellite based solar radiation data" [Online]. Available: http://re.jrc.ec.europa.eu/pvgis/download/solar_radiation_cmsaf_downlo ad.html. [Accessed 27 July 2016].

[8] RenSMART, "NOABL Wind Map" [Online]. Available: http://www.rensmart.com/Weather/BERR

[9] WEBvision, "Renewables (Wind)" [Online]. Available: http://vision.abpmer.net/renewables/map_default.phtml?config=wind\&

[10] M.-H. Yang, R.-H. Yeh. "Analysis of optimization in an OTEC plant using organic Rankine cycle," Renewable Energy, vol. 68, pp. 25-34, Aug. 2014.

[11] Carbon Trust. "Tidal Stream - Phase II: UK Tidal Stream Energy Resource Assessment. Marine Energy Challenge" [Online]. Available: http://www.lunarenergy.co.uk/Userimages/PhaseIITidalStreamResource Report.pdf [Accessed 12 August 2016].

[12] A. Leitner, B. Owens. "Brighter than a hundred suns: Solar power for the Southwest," National Renewable Energy Laboratory, Golden, CO, Rep. NREL/SR-550-33233, 2003.

[13] BritGeothermal, "BritGeothermal UK potential" [Online]. Available: http://www.britgeothermal.org/research/uk.html [Accessed 12 Aug. 2016].

[14] J.W. Lund, T.L. Boyd. "Direct utilization of geothermal energy 2015 worldwide review," Geothermics, vol. 60, pp. 66-93, Mar. 2016.

[15] Cornwall Council. "An assessment of the renewable energy resource potential in Cornwall," Technical Paper E2, 2013.

[16] RenSMART, "PVGIS Solar Map" [Online]. Available: http://www.rensmart.com/Weather/PVGISSolar. [Accessed 15 June 2016].

[17] DECC, "Small scale hydroelectric generation potential in the UK," Salford Civil Engineering Ltd., Rep. ETSU-SSH-4063-P1, vol.1, 1989.

[18] Natural Resources Wales, "River levels online" [Online]. Available: http://www.naturalresources.wales/our-evidence-and-reports/maps/riverlevels-online?lang=en. [Accessed 15 August 2016].

[19] UK Government, "River and sea levels in England," Crown Copyright, 25 August 2016. [Online]. Available: https://flood-warninginformation.service.gov.uk/river-and-sea-levels. [Accessed 25 August 2016].

[20] ESRI, "Mapping Without Limits" [Online]. Available: https://www.arcgis.com/features/index.html. [Accessed 25 June 2016].

[21] J.A. Carrion, A.E. Estrella, F.A. Dols, M.Z. Toro, M. Rodriguez, A.R. Ridao. "Environmental decision-support systems for evaluating the carrying capacity of land areas: Optimal site selection for grid-connected photovoltaic power plants," Renewable and Sustainable Energy Reviews, vol. 12, pp. 2358-2380, Dec. 2008. 